London, UK

jacqui@jacquithornton.com Cite this as: BMJ 2020;371:m4098 http://dx.doi.org/10.1136/bmj.m4098 Published: 26 October 2020

\section{What can the UK learn from the southern hemisphere winter?}

\section{Australia, New Zealand, and South Africa have all been through a covid-19 winter with flu virtually absent-how can the NHS use their experience, asks Jacqui Thornton}

\section{Jacqui Thornton freelance journalist}

As the UK's winter draws in, the southern hemisphere is enjoying spring. Despite dire predictions, it appears to have experienced a welcome side effect of covid-19: lower transmission of respiratory diseases.

Australia, New Zealand, and South Africa, as well as Argentina, Chile, and Paraguay, "skipped" the flu season in 2020. ${ }^{1}$ New Zealand death rates at the height of winter were the lowest absolute figure since 2016 (including only 25 covid-19 deaths ${ }^{2}$ ); when accounting for population growth, it is the lowest death rate per 100 ooo people in at least 10 years, the period for which data are available. ${ }^{3}$ Flu has been almost non-existent with a peak of $0.8 \%$ of people self-reporting flu like symptoms. ${ }^{4} \mathrm{GP}$ surveillance has found no confirmed cases. ${ }^{5}$

The influenza pattern was similar in other countries: in one study, only 33 influenza positive test results were detected among 60031 specimens tested in Australia, 12 among 21178 specimens tested in Chile, and six among 2098 specimens tested in South Africa. $^{6}$

Experts say that rather than it being a less virulent year, measures against covid-19-lockdowns, school closures, mask wearing, and social

distancing-almost certainly had an impact. "Because influenza is transmitted in much the same way as covid-19, the steps used to control covid-19 are likely to be even more effective against flu, given the lower $\mathrm{R}$ value for seasonal flu because of pre-existing population immunity," says Paul Hunter, professor in medicine at the University of East Anglia.

Bharat Pankhania, communicable disease specialist and senior clinical lecturer at the University of Exeter, puts it more directly: "When covid-19 arrives, people take cover. As a result of extra hand hygiene, social distancing, and other precautions, there are fewer other infections."

\section{UK expectations}

Many commentators agree that it is likely a similar pattern will follow in the UK-though we should not take it for granted. Schools remain open and, as influenza spreads readily through children, an outbreak is not impossible.

Plus, it is hard to make comparisons with countries in the southern hemisphere because there are variables and differences-not least that their winters are warmer than ours and complying with staying outside will be harder in the UK.

Julian Tang, honorary associate professor in respiratory sciences and clinical virologist at the University of Leicester, says compliance with covid-19 measures has likely been variable in both Australia and the UK-and, though the overall principles are similar, fine details differ. For example, Australia recommended $1.5 \mathrm{~m}$ social distancing versus the UK's $2 \mathrm{~m}^{7}$

Public Health England says that what happens in Australia is not a clear predictor of the UK's flu season, because the former spans tropical and sub-tropical latitudes while the UK is temperate and so seasonality is generally more consistent.

The timing and intensity of flu in the UK is more dependent upon factors such as population immunity (from prior infection and vaccination), local weather conditions, the dominant circulating strain, and how closely matched it is to prior strains and the season's vaccine.

Vanessa Saliba, head of flu at Public Health England, told The BMJ, "We cannot be complacent, the southern hemisphere's season doesn't necessarily imply that the UK will have a similar experience and many factors are at play. For example, other strains of flu could still emerge, and the actual impact may be modified depending on what type of social distancing is in place.”

Ian Higginson, vice president of the Royal College of Emergency Medicine, says he is not aware of any plans to change service delivery because of any anticipated reduction in respiratory conditions. Higginson, a consultant in Plymouth who did his postgraduate training in New Zealand, says it is unlikely that anyone knows whether the experience of the southern hemisphere is a reliable predictor of what will happen in the UK. "I'm not sure we can learn anything from their experience other than it's possible that the measures taken to reduce the spread of covid-19 have an impact on the spread of other respiratory diseases," he said. "There are a lot of factors that can contribute to how good or bad a flu season is. And those in the southern hemisphere are going to be potentially quite different to the factors that we experience over here.”

\section{Vaccination}

Another reason for a predicted quiet flu season in the UK is an anticipated high uptake of the influenza vaccination. In South Africa, many people rushed to clinics to get flu shots once covid-19 cases rose, hoping to avoid at least one comorbidity. ${ }^{8}$

In September, the UK's Department of Health and Social Care announced its biggest flu vaccination programme to date, aiming to immunise 30 million people. ${ }^{9}$ But, so far, the programme has had supply problems. Boots suspended NHS and private flu vaccination bookings for under 65s in September, 
citing "unprecedented levels of demand." ${ }^{10}$ After extending the free vaccination to the over 50s, NHS England then confirmed that eligibility will only be extended to those aged 50-64 "if circumstances permit." 11

One US paediatrician has posited that flu vaccination may increase the likelihood of catching covid-19. ${ }^{12} 13$ Doctors who spoke to The $B M J$ said there was no evidence for this, and that it was inherently unlikely. Tang says Australian research suggests vaccination may enhance host immune responses overall in a possibly beneficial way. ${ }^{14}$

Yvonne Doyle, medical director at Public Health England, says that the flu vaccine is more important than ever, to help reduce transmission of flu and protect the nation from a "double threat" of flu and covid-19, which would pose problems for an NHS where intensive care beds are already filling up. Last winter in the UK, flu came early, so the two viruses did not overlap much.

\section{Twin epidemic}

This year's flu could be worse than expected. There is mixed opinion as to what that would mean for vulnerable patients if there were a twin epidemic-some believe this would provoke a double assault on the lungs, others think that an inflammatory response from one virus would prevent the second taking hold.

Research from PHE, published on 22 September as a preprint and not peer reviewed, ${ }^{15}$ suggests the risk of death more than doubled for people who tested positive for both flu and covid-19, compared with those with covid-19 alone.

Where there is consensus is the impact on capacity if there were a twin epidemic. Surveillance for the two diseases is closely integrated and PHE is encouraging healthcare workers to test patients for flu alongside covid-19 where possible.

Mike van der Watt, chief medical officer at West Hertfordshire Hospitals NHS Trust, says staff are testing all emergency department patients on arrival and the trust's new in-house tests offer simultaneous testing for flu, covid-19, and other common respiratory pathogens. He adds, "The impact of a dual epidemic is clearly a concern, but the Australian experience suggests that widespread mask use significantly reduced the seasonal impact of flu."

The fact that the two have very similar symptoms will cause pressure on the covid-19 testing system, creating more capacity problems, as well as personal anxiety, according to Pankhania.

Jeremy Brown, professor of respiratory infection at UCL and a member of the British Thoracic Society, says that if we did have a significant flu season he believes it could occur "back-to-back" with covid-19, delayed because of social distancing. So, covid-19 might be over and done with before flu hits, though that would still be "pretty exhausting” for hospital staff.

Emergency medics are considering ways to minimise cross infection when winter hits, as well as how to deal with the usual capacity problems and staff absences from illness. Higginson says one challenge is space. "Patients must be kept safe in emergency departments from the effects of covid-19. We can't have patients in our corridors. We kept patients squashed together in the past, but it's never been the right thing to do. This demonstrates how wrong it was."

Martin McKee, professor of European Public Health at the London School of Hygiene and Tropical Medicine, says this point is fundamental. It's why countries hit by SARS redesigned their health facilities to reduce the risk of infections. He adds, "One of the reasons the UK has been hard hit is because of underinvestment in the health service for so long-when something like covid-19 comes along we can't cope."

Research he and colleagues conducted on high death rates in 2015-with a notable spike in January-posited that it was not flu alone that increased mortality but a health system unable to cope following large scale cuts. ${ }^{16}$

McKee says there is something we can learn from the southern hemisphere's winter experience: it makes us realise that there are other things we can do in addition to vaccination to tackle flu-concentrating on ways we can reduce airborne transmission. "This is an opportunity to reassess the way we look at these things," he says.

Brown agrees, noting that the vaccine "varies in efficacy.” But he doesn't think yearly measures are feasible, practically speaking. "It isn't really politically or socially sustainable to have that sort of isolation installed on an annual basis.”

\section{Competing interests: None declared.}

Commissioned, not externally peer reviewed.

The southern hemisphere skipped flu season in 2020. Economist. 12 September 2020.www.economist.com/graphic-detail/2020/09/12/the-southern-hemisphere-skipped-fluseason-in-2020.

WHO. Covid-19: New Zealand. https://covid19.who.int/region/wpro/country/nz. Mitchell C, Daly M. Coronavirus: while covid-19 takes lives around the world, New Zealand's response has led to fewer deaths from all causes. Stuff. 19 August 2020. www.stuff.co.nz/national/health/coronavirus/122476223/coronavirus-while-covid19-takes-lives-around-the-worldnew-zealands-response-has-led-to-fewer-deaths-from-all-causes.

4 Flu Tracking. Flutracking reports (New Zealand). https://info.flutracking.net/reports-2/new-zealandreports.

5 Science for Communities. Flu surveillance and research. www.esr.cri.nz/our-services/consultancy/flu-surveillance-and-research.

6 Olsen SJ, Azziz-Baumgartner E, Budd AP, et al. Decreased influenza activity during the covid-19 pandemic-United States, Australia, Chile, and South Africa, 2020. MMWR Morb Mortal Wkly Rep 2020;69:1305-9. doi: 10.15585/mmwr.mm6937a6 pmid: 32941415

7 New South Wales government. What you can and can't do under the rules. www.nsw.gov.au/covid-19/what-you-can-and-cant-do-under-rules.

8 Wroughton L. Flu was all but eliminated in South Africa this year. Coronavirus is to thank. Washington Post. 18 August 2020. www.washingtonpost.com/world/africa/south-africa-coronavirus-flu-season/2020/08/17/bd8aaaca-e084-11ea-82d8-5e55d47e90ca_story.html.

9 Public Health England. Press release: Record numbers offered flu vaccine as those with flu and covid-19 more likely to die. 22 September 2020. www.gov.uk/government/news/record-numbersoffered-flu-vaccine-as-those-with-flu-and-covid-19-more-likely-to-die.

10 Jankovic S. Boots suspends under-65s flu jab bookings amid "unprecedented" demand. Pulse Today. 23 September 2020. www.pulsetoday.co.uk/news/clinical-areas/immunology-and-vaccines/boots-suspends-under-65s-flu-jab-bookings-amid-unprecedented-demand.

11 Pearce C. GP clinics face "uncertainty" as NHSE confirms 50-64s "may" not get flu jabs. Pulse Today. 5 October 2020. www.pulsetoday.co.uk/news/clinical-areas/immunology-and-vaccines/gpclinics-face-uncertainty-as-nhse-confirms-50-64s-may-not-get-flu-jabs.

12 Cunningham AS. The vexed question of flu shots and the risk of covid-19 [electronic response to Megget K. Even covid-19 can't kill the anti-vaccination movement]. BMJ 2020. www.bmi.com/content/369/bmi.m2184/rr-4.

13 Cunningham AS. Flu shots and the risk of coronavirus infections [electronic respoinse to Watkins J. Preventing a covid-19 pandemic]. BMJ 2020. www.bmj.com/content/368/bmj.m810/rr-0.

14 Thevarajan I, Nguyen THO, Koutsakos M, et al. Breadth of concomitant immune responses prior to patient recovery: a case report of non-severe COVID-19. Nat Med 2020;26:453-5. doi: 10.1038/s41591-020-0819-2 pmid: 32284614

15 Stowe J, Tessier E, Zhao H, et al. Interactions between SARS-CoV-2 and influenza and the impact of coinfection on disease severity: a test negative design.MedRxiv 2020.09.18.20189647 [Preprint]. 2020

16 Excess deaths in 2015 may be linked to failures in health and social care. 17 February 2017. London School of Hygiene and Tropical Medicine. www.Ishtm.ac.uk/newsevents/news/2017/excess_deaths_2015_failures_health_social_care.html. 